\title{
Implications of Internet Availability of Genomic Information for Public Health Practice
}

\author{
B.W. Hesse ${ }^{a}$ N.K. Arora ${ }^{a}$ M.J. Khoury ${ }^{a, b}$ \\ ${ }^{a}$ National Cancer Institute, National Institutes of Health, Bethesda, Md., and ${ }^{b}$ Office of Public Health Genomics, \\ Centers for Disease Control and Prevention, Atlanta, Ga., USA
}

\section{Key Words}

Direct-to-consumer advertising • Health communication • Internet · Self-regulation

\begin{abstract}
Tensions in the field have emerged over how best to communicate to the public about genomic discoveries in an era of direct-to-consumer (DTC) DNA testing services available through the Internet. Concerns over what the psychological and behavioral response might be to a nuanced, multiplex risk message have spurred some to offer caution in communicating to the public about personalized risk until the necessary research has been completed on how to communicate effectively. The popularization of DTC testing services, along with a spreading Internet culture on transparency for personal data, may make 'waiting to communicate' a moot point. To steer communication efforts in the midst of increasing access to personal genomic information, a self-regulation framework is presented. The framework emphasizes the importance of presenting a coherent message in all communiqués about public health genomics. Coherence should be based on an evidence-based model of how the public processes information about health conditions and an emphasis on risk-to-action links. Recommendations from the
\end{abstract}

President's Council of Advisors for Science and Technology are reviewed as a way of identifying targets of opportunity for structured communications both within the healthcare system and in the broader external ecosystem of publicly available health information technologies.

Copyright $\odot 2012$ S. Karger AG, Basel

\section{Tensions in the Field}

A study published in the Journal of Health Psychology in 2009 illustrates a tension that has been building in the field of public health genomics over the past decade [1]. At issue is what to do in communicating the science of genomics research to the general public when the links between specific genetic variants and patterns of disease are poorly understood and probabilistic [2-6]. The problem is amplified by characteristics of a rapidly changing communication environment in which genomics-related stories and direct-to-consumer (DTC) genetic testing services are allowed to proliferate through new media channels in largely unfettered ways. The questions have to do with understanding, from a behavioral perspective, what the average consumer will do when learning about a link between some aspect of their genetic makeup and

\section{KARGER}

Fax +4161306 1234

E-Mail karger@karger.ch

www.karger.com
(C) 2012 S. Karger AG, Basel

$1662-4246 / 12 / 0154-0201 \$ 38.00 / 0$

Accessible online at:

www.karger.com/phg
Bradford W. Hesse, $\mathrm{PhD}$

National Cancer Institute

6130 Executive Boulevard, MSC 7365

Bethesda, MD 20892-7365 (USA)

Tel. +1 301594 9904, E-Mail hesseb@ mail.nih.gov 
a specific disease process [2]. Upon learning such information, will consumers infer an inappropriate sense of determinism and consequently refrain from engaging in risk-reductive behaviors related to that process [3]? For example, if consumers learn that the tendency to overproduce cholesterol (e.g. hypercholesterolemia or hyperlipidemia) is genetically predisposed in some people, but not in others, will those same consumers infer an inappropriate sense of invulnerability for themselves and thus give up on their own intentions to modify their diets?

To address the question, the study's authors exposed participants to simulated news reports describing the general link between genetic factors and salt sensitivity in 1 set of studies (studies $1 \mathrm{a}$ and $1 \mathrm{~b}$ ) and genetic factors and heightened cholesterol production in another (study 2). Participants' awareness of these factors was assessed ahead of time, with a general assumption that those who were unaware of these links would show a greater effect from the news stories than those who already knew about them. That is, the presentation of a news story explaining that some people are at greater risk for certain ailments than others would lower a sense of pervasive danger within the general population; and, in the absence of personal risk information, may dissuade people from modifying their own personal behaviors until they gained further understanding. Following the investigators' predictions, those who were unaware of the links beforehand were more likely to report lower perceptions of risk and decreased intentions to modify diet than those who were already aware of those links. With these results in-hand, the authors concluded: 'We are thus in dire need of more empirical research on this matter before informing the general public about the existence of genetic risk factors, and especially before deciding on a specific strategy to do so' $[1]$.

This cautionary conclusion - that genetic risk information should not be communicated to individuals or the public until more conclusive research has been conducted - stands in stark contrast to the world of DTC genetic testing promulgated broadly through the Internet. In general, the ethos within 'the Culture of the Internet' [7] is one of transparency. Born from the counterculture of the 1960's and 1970's, the motivating principles underlying the personal computing revolution of the 1980's and the online Internet revolution of the 1990's were based on the concept that 'information is power' and that gaining free and open access to information is a desirable end [8]. There is some indication that the public has begun to embrace that ethos with respect to health information and has grown accustomed to searching for, and utilizing, online health information in substantial numbers [9]. The question is: what might the implications be of creating unfettered access to the nuanced, technically sophisticated, sometimes conflicting, occasionally wrong, and probabilistic information of DTC genetic tests for consumer health?

\section{A Natural Experiment}

Philosophical tensions aside, the public has been engaged in a natural experiment over the past 2 decades in which data and information about health have been made broadly accessible through networking and information technologies. In this sense, the debate over whether to keep communications about genetic risk factors over the Internet at bay until more scientific studies have been conducted has largely been made moot. A systematic review reported that there were 27 different online, DTC testing companies in 2007 [10]. Patient advocates have since been lobbying for greater access to data about their physiologic functions, from quantified measures of daily metabolism to personalized assessments of genetic predilections [11]. In a 2011 conference on 'Open Government' hosted at the US National Archives, a biostatistician explained that rather than being put off by difficult-to-understand statistics about their care and treatment, many patients are arguing for access to their own data as a 'civil right' [12]. Patient advocates have summarized their sentiments about sharing data for care or research with the slogan 'no data about me without me' [11].

\section{Diffusion of Online Health Information}

What, then, have the results been of this natural experiment in open data access? In 1999, the estimated number of adults using the Internet in the US lingered at around $37 \%$ of the total population [13]. Internet penetration among adults climbed to $63 \%$ by 2003 [14] followed by estimates of $68 \%$ in 2008 [15] and $78 \%$ in 2010 [13]. In 2005 , an estimated 76,502,088 people went online to look for health information for themselves or their loved ones [14]. Of those who went online in 2008, about a quarter - or 33,973,131 adults - reported talking about what they found online with their doctor or other health professional. In 2008 , roughly $14.4 \%$ of those online $(22,114$, 887 ) reported buying medicine or vitamins online; $13.5 \%$ reported using e-mail to communicate with their doctor or doctor's office; and $4.9 \%(7,584,731)$ participated in an online support group with people having similar health or medical conditions [15]. In 2008, an estimated $29.2 \%$ 
of American adults - or 64,300,922 people - reported having heard or read about tests 'marketed by companies directly to consumers' to assess 'DNA, diet and lifestyle for potential risks.' An estimated $8.1 \%$ of American adults - or 5,245,012 people - in the same survey said that they had taken such a test.

On the supply side, the total number of websites available to the public climbed from a meager 130 reported in June of 1993, to 2,410,067 in 1999 and then grew exponentially to over $250,000,000$ by July of 2010 [16]. The number of references accumulated when entering in the specific pharmaceutical term 'Femara' (an aromatase inhibitor used in the treatment of breast cancer) on the open Web in 2001 was 1,060 [17], while the same search yielded 1,730,000 references in 2009 and 7,100,000 in 2011. Daily e-mail traffic rose from 12 billion in 2000 to 247 billion in 2010; active blogs rose from 12,000 in 2000 to 141 million in 2010; and daily Google ${ }^{\circledR}$ searches rose from 100 million in 2000 to 2 billion in 2010 [18].

Although discussion groups and chat rooms were around in 1999, many observers could not have foreseen the rise of social participation websites that would lead some to declare an evolution from Web 1.0 to Web 2.0 [19, 20]. Through the participative environs of Web 2.0, persons diagnosed with serious disease could share their stories in video through YouTube [21]; form networks of support around them through Facebook ${ }^{\circledR}$ [22], CaringBridge $^{\circledR}[23]$ and Twitter ${ }^{\circledR}$ [24]; and even seek out similarly diagnosed others for sharing data on treatments through PatientsLikeMe ${ }^{\circledR}$ [19]. Nor could they have foreseen a circumstance in which thousands of consumers would willingly pay money to order a cheek swabbing kit from the online DTC genomic company ' $23 \mathrm{AndMe}^{\circledR}$ ' and then contribute data from the genetic analysis of their samples to replicate an NIH-funded study that originally took 6 years to complete, cutting the completion time down to 8 months [25].

\section{Risks and Cautions}

As Internet usage spreads, a number of panels and authors offered warnings on what some of the negative consequences of accessing online health information might be. Among some of the concerns expressed were worries that: (a) information of dubious quality might cause malevolent effects [26, 27], (b) that too much information available online might cause a sense of escalating confusion [28-30] and (c) that the availability of alternative sources of credible medical information might erode patients' trust in physicians [28, 31].

Internet and Genomics
What about these negative forecasts? Have they materialized to the degree cautioned by many of these early commentaries? Here, the evidence is mixed. The prevalence of questionable websites, foisting unfounded remedies and offering seemingly objective evidence as a mask for ulterior profit motives, has undoubtedly increased along with the general growth of the Web [32]. By moving facilely beyond borders, companies have used loopholes in international eCommerce to get around domestic restrictions in selling cigarette products to minors [33] and prescription drugs to those without a physician's approval $[34,35]$. Online networks have produced new types of fraud and predatory consumer practices (e.g. 'phishing', 'bot-nets' and pump-and-dump securities schemes). Because of the rapidity associated with online social networks, health myths can now 'go viral,' disseminating just as quickly as any evidence-based health finding [36].

In spite of the proliferating opportunities for deception, however, the public has shown some degree of resilience when it comes to dealing with misleading health information on the Web [37, 38]. Stories of patients who abandon their physicians' advice to follow the dangerous exhortations of consumer-oriented websites are rare and are no more prevalent than in offline conversations. In fact, there might be some evidence to suggest that under certain conditions the connective properties of online media may serve to combat the problems of information isolation often experienced by those struggling with health problems on their own. When someone hears of a questionable health suggestion (e.g. smoking is a good way to lose weight), they can go online and check that supposition out against the collective conclusions of others like themselves [39]. Similarly, stories abound of people who may have encountered a potential symptom and were unsure of what to do about it, but by exploiting the strength of 'weak ties' on the Web were able to get informational support on what to do [22, 40,41]. Getting a second opinion, and even a third or fourth opinion, through online discussion groups can help patients triangulate on the best therapeutic choices to discuss with their care teams, whereas those who find themselves isolated offline must struggle with a limited number of (often uniformed) opinions from friends or family [41, 42].

What may be missing in the unregulated environs of the Web, though, is careful attention to the interpretative information that patients may need to make sense of the cacophony of data available in a rapidly changing and highly populated information environment. Data from the Health Information National Trends Survey suggest that confusion over the causes and clear paths for preven-

Public Health Genomics 2012;15:201-208 
Fig. 1. Using the Common Sense Model of Disease to create coherence between risk messages (genetic susceptibility) and action plans (behavior): Adapted from Cameron and Leventhal (2003) The Self-Regulation of Health and Illness Behaviour, p 50.

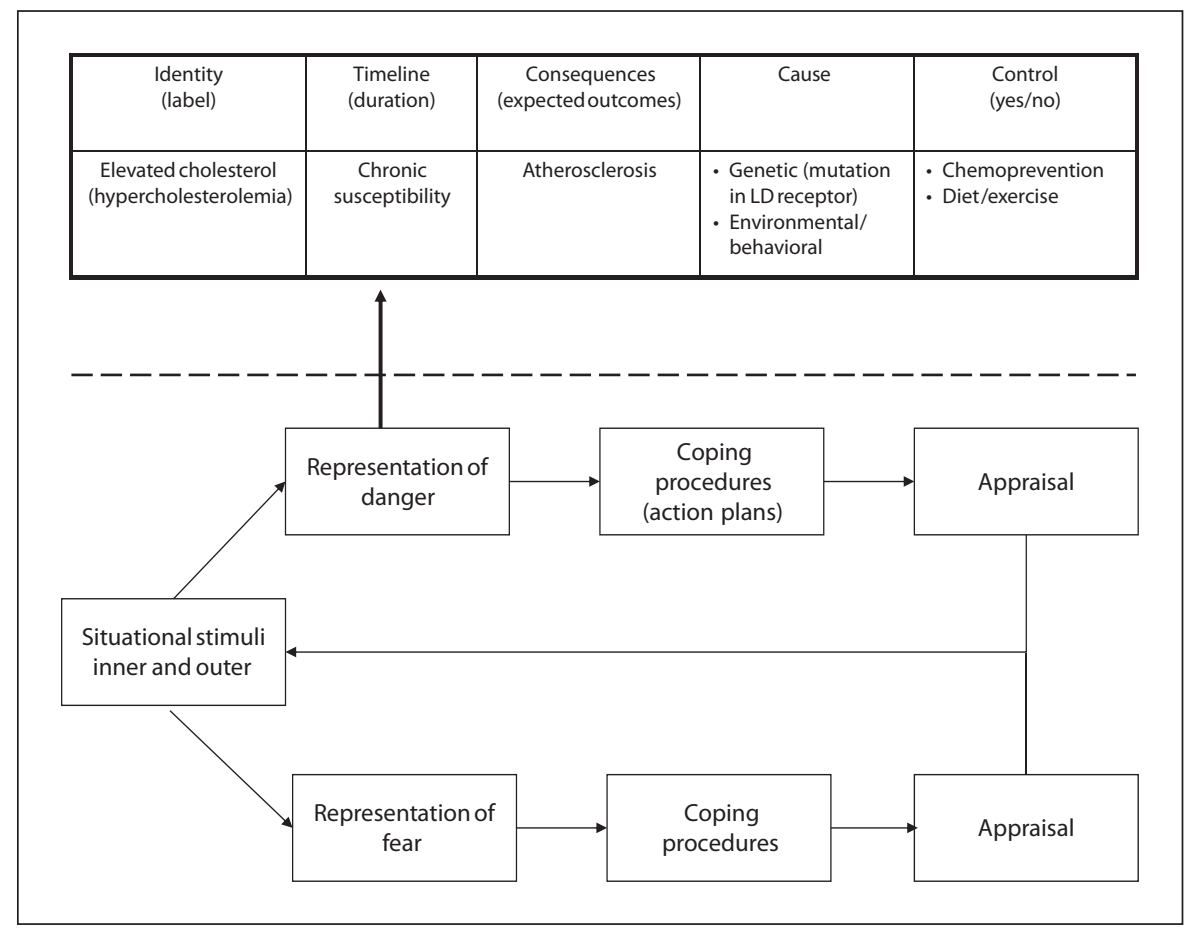

tion against such complex genetic diseases such as cancer is increasing. Results portrayed a $7.7 \%$ increase in the already high percentage of people who strongly or somewhat agreed with the statement that it seems almost everything causes cancer' from 2003-2005 and a 3.7\% increase in the already substantial number of people who agreed with the statement that 'there are so many recommendations about preventing cancer it's hard to know which ones to follow' [43]. In a social media (i.e. Facebook) survey of the public's opinions regarding DTC genetic test results, researchers found that the general public tended to believe that the probabilistic results of DTC tests would be more useful than did genetic counselors. The investigators concluded that more research would be needed to provide DTC test results in ways that minimize risk of misinterpretation by consumers [44].

This trend of seeking the input of others to improve decision-making does not necessarily mean that patients are using online networks to replace the professional council of their doctors; in fact, just the opposite may be true. Data from the Health Information National Trends Survey showed increasing levels of trust in their medical teams and at the same time that levels of Internet usage as a source of first resort for health information were climbing $[15,45]$. These data suggest that the ways in which information technology is insinuating itself within the professional-consumer relationship is different in medicine than it is in other industries, such as travel. In other industries, customers 'cut out the middleman' to go straight to the source for buying products and services, a term referred to as disintermediation. Within health care, both patients and their care teams are constantly being surrounded by new information in health. Both sides appear to be working together to make sense of the burgeoning information explosion, with professionals bringing experience and education and patients bringing their values and self-knowledge to the encounter [46]. In this new environment, consumers may still need a clear path to medical professionals in order to interpret the findings of online health information $[47,48]$.

\section{Building a Framework for Reducing Uncertainty}

To understand how to reduce uncertainty regarding the findings of genomic tests promulgated through the Web, it is useful to consider the ways in which people process information about disease and health conditions. One useful model that can serve as a guide is the common sense model of disease introduced by Cameron and Leventhal [49] as depicted in figure 1. According to 
this basic information processing model, individuals are exposed to informational stimuli both from the external environment (e.g. DNA analyses of endogenous vulnerability) and from the internal, cognitive environment (e.g. contemplating, synthesizing and processing for 'gist'). Individuals use that information to derive coping strategies for perceived threats. This particular framework is referred to as a 'dual process' model because it acknowledges that neural stimuli are likely to trigger parallel processes, both down a highly automatic, affectladen path and a more rational, action-oriented path. A key to successful communication based on the model is the importance of providing a clear risk-to-action link so that individuals can adopt adaptive coping strategies. If that 'safety information' is not given, and the individual is incapable of addressing the health threat with action, they may resort instead to resolving their own internal tensions psychologically. They may feel paralyzed and confused as to what to do. As a consequence, they may seek to avoid future communications on similar subjects or simply rationalize their own lack of precaution [49, 50].

Cameron and Leventhal [49] have also been successful in understanding how consumers think about the process of disease. In the top part of figure 1, above the dashed line, is a representation of the cognitive schemata [51] (or mental model) that most people follow when interpreting information about health conditions. Quite commonly they look first to give the condition-in-question a name (e.g. risk for high cholesterol). They then seek to understand the timeline and temporal qualities of the condition. Is this an acute condition or a chronic condition? Does the condition require immediate attention now or does it simply require an attitude of watchful waiting? Most people also want to know what might be causing the condition and, in very related way, what that means for creating an action plan for controlling the risk. Here, the delicate balance between endogenous and exogenous factors becomes important. To what degree is the condition inherited, and if it is inherited can something be done to cope with the risk perhaps through chemoprevention, behavioral modifications or routine screening? Some risks cannot be controlled, and if that is the case then people need to know that so they can adjust their psychological appraisals appropriately. Studies suggest that long-term understanding can be improved and adaptive health behaviors can be nurtured by delivering information in a way that conforms to this common sense model of disease [49, 52-54].
A study by Cameron et al. [55] illustrates how the selfregulation model can be used to evaluate Internet-based presentations of genetic risk information. In an Internetbased experiment across 4 countries, the team evaluated responses from 749 adults to messages about a hypothetical test for colon cancer risk. Messages varied by riskaction link information, in this case the provision or no provision of information on how a low-fat diet would reduce risk given the presence of a positive result on the hypothetical genetic test. According to their results, providing risk-action link information appeared to improve participants' coherent understanding of the disease process, it improved their sense of response efficacy (faith that behavioral action will reduce the risk), and it lowered appraisals of anticipated risk given positive results on the hypothetical test.

\section{Implications for Public Health Practice}

Within the context of an emerging health information ecosystem, should public health practitioners take precautions to protect consumers from some types of DTC genetic information? In one sense, the answer is an emphatic 'yes'. Anytime a biotechnology firm advertises a product that purports to give information on personal physiologic conditions, the veracity of those claims should be open to verification through government oversight or consumer group vigilance [56]. Misrepresented claims or shoddy assessments should be brought to the attention of the appropriate boards and regulatory bodies to correct for informational malpractice. More broadly, the public health agenda should continue the pursuit of a credible and reliable scientific evidence base to undergird productive use of genomic technologies in medicine and beyond [57].

The real challenge, though, may not lie in excluding personal genetic information from online information seekers prematurely, but in creating better informational resources for improving consumer understanding [58]. As explained by a previous director of the National Institutes of Health to members of Congress, medicine in the 21st Century is geared toward creating a public health environment that is increasingly more predictive, preemptive, personalized, and participative [59-61]. Empowering patients with a clear and evidence-based understanding of their own individualized risk profiles, and then supporting healthy decision-making over the lifespan in consultation with medical professionals, is fully consistent with recommendations for quality im- 
provement and cost reductions in healthcare offered by the Institute of Medicine [62,63]. Using a public health framework for communication that will give patients a better understanding of the probabilistic processes guiding their own health, while providing them with the predictive data and coherent courses of action to self-regulate behavior, lies at the heart of recommendations for patient-centric reform in healthcare and science $[17,64-$ 66].

\section{Improving Communication within Healthcare}

In December 2010, the US President's Council of Advisors of Science and Technology delivered 2 reports relevant to the task of creating a more supportive information environment for the public and for patients. The first one, titled 'Realizing the Full Potential of Health Information Technology to Improve Healthcare for Americans: The Path Forward' [67], provided technical detail to the national task of infusing healthcare with reliable information systems to support better care. The report built on the Congressional mandate for building healthcare systems that are safe and effective, engaging to patients, continuous across providers, supportive of population health, and secure. Within this idealized environment are a number of opportunities for building the safeguards needed to optimize consumers' understanding of genetic risk. For example, efforts are underway to incorporate genetic risk information within the standard reporting capacity of electronic health records. Health systems are creating their own web-based portals to an individual's electronic health records data, referred to as a tethered Personal Health Record system. In this context, every interface has the potential of serving as a communication intervention: that is, in providing the standardized presentation of genetic risk information to both the clinical team and the patient that conforms to best practice in human factors research and user-centered design. Record keeping systems and built-in communication channels (e.g. through secure e-mail) can also serve to bring patients in reliable contact with the genetic counselors, primary and specialty care physicians, nurses, and other team members to resolve confusion.

Improving Communication through the Open Internet The other report, titled 'Designing a Digital Future: Federally Funded Research and Development in Networking and Information Technology' [68], focused on the evolution of Internet-based technologies outside of the healthcare system. This report emphasized the interactive and socially connective nature of the evolving infor- mation environment outside of healthcare and suggested that new research be conducted to 'enable both professionals and the public to obtain and act on health knowledge from diverse and varied sources as part of an interoperable health IT ecosystem.' An important theme in this regard is the recognition that the public information environment is evolving beyond a one-way, mass medium model only, to a 'many-to-many' Internet-mediated environment for shared understanding. Research conducted by Cappella [69] within an NCI-funded Center of Excellence on Cancer Communication Research, for example, demonstrated that it is possible to improve the presentation of genetic discovery to the public by linking reporters directly with scientists. Recognizing that traditional news environments are rapidly evolving to take full advantage of online communication channels, it is possible to envision a system that could help improve public health reporting in genomic science. It is also possible to envision advanced networking and information technology techniques that could help citizens participate more directly in the advancement of scientific knowledge [70, 71].

\section{Conclusion}

By all indications, the fields of medicine and public health are at a serious inflection point. The strengths of industrial age medicine, with an emphasis on mass-produced 'one-size-fits-all' treatments applied late in the pathological progress of disease, are turning into financial and biological liabilities. The field of public health, which has been struggling to define its boundaries in a rapidly changing context of policy change and community self-organizing, is gearing up to deal with the consequences of globally spreading chronic disease. Innovation is needed to ensure that the petabytes of data being produced by improved cost-efficiencies within the gene sequencing industry are marshaled for discovery and public health translation. As genomic pioneer Venter [66] declared, patients - equipped with cutting edge access to their own DNA - may soon be the co-creators of biomedical discovery within wholly new public health environments. Without attending to the psychosocial consequences of communicating genetic information effectively within these new environments, however, that opportunity may only give way to escalating confusion. 


\section{References}

$>1$ Smerecnik CM, Mesters I, de Vries NK, de Vries H: Alerting the general population to genetic risks: the value of health messages communicating the existence of genetic risk factors for public health promotion. Health Psychol 2009;28:734-745.

$\checkmark 2$ Khoury MJ, Thrasher JF, Burke W, Gettig EA, Fridinger F, Jackson R: Challenges in communicating genetics: a public health approach. Genet Med 2000;2:198-202.

$>3$ McBride CM, Koehly LM, Sanderson SC, Kaphingst KA: The behavioral response to personalized genetic information: will genetic risk profiles motivate individuals and families to choose more healthful behaviors? Annu Rev Public Health 2010;31:89-103.

4 Khoury MJ, Coates RJ, Evans JP: Evidencebased classification of recommendations on use of genomic tests in clinical practice: dealing with insufficient evidence. Genet Med 2010;12:680-683.

$>5$ National Heart, Lung, and Blood Institute working group, Fabsitz RR, McGuire A, Sharp RR, Puggal M, Beskow LM, Biesecker LG, Bookman E, Burke W, Burchard EG, Church G, Clayton EW, Eckfeldt JH, Fernandez CV, Fisher R, Fullerton SM, Gabriel S, Gachupin F, James C, Jarvik GP, Kittles R, Leib JR, O’Donnell C, O’Rourke PP, Rodriguez LL, Schully SD, Shuldiner AR, Sze RK, Thakuria JV, Wolf SM, Burke GL: Ethical and practical guidelines for reporting genetic research results to study participants: updated guidelines from a National Heart, Lung, and Blood Institute working group. Circ Cardiovasc Genet 2010;3:574-580.

$\checkmark 6$ Croyle RT, Lerman C: Risk communication in genetic testing for cancer susceptibility. J Natl Cancer Inst Monogr 1999;25:59-66.

7 Kiesler S (ed): Culture of the Internet. Mahwah, Psychology Press, 1997.

8 Markoff J: What the Dormouse Said. New York, Penguin, 2005.

9 Fox S: Health Topics: $80 \%$ of Internet Users Look for Health Information Online. Washington, DC, Pew Research Center, 2011.

$\checkmark 10$ McBride CM, Wade CH, Kaphingst KA: Consumers' views of direct-to-consumer genetic information. Annu Rev Genomics Hum Genet 2010;11:427-446.

11 deBronkart D, Kuraitis V, Kibbe DC: Gimme My Damn Data! The Health Care Blog, May 7, 2010.

12 Stodden V: Data Transparency in Health. Open Government Research and Development Summit. Washington, DC, National Archives, 2011.

13 Pew Research Center: Internet Adoption, 1995-2011. Pew Foundation 2011. http://www. pewinternet.org (accessed September 5, 2011).

14 Rutten LF, Moser RP, Beckjord EB, Hesse BW, Croyle RT: Cancer Communication: Health Information National Trends Survey. Washington, DC, National Cancer Institute, 2007. NIH Pub. No. 07-6214.
15 Hesse BW, Moser RP, Rutten LJ: Surveys of physicians and electronic health information. N Engl J Med 2010;362:859-860.

16 Hobbes Zakon R: Hobbes' Internet Timeline 10.1. 2010. http://www.zakon.org/robert/ internet/timeline/ (accessed September 5, 2011).

17 Hesse BW: Enhancing consumer involvement in health care; in Parker JC, Thornson E (eds): Health Communication in the New Media Landscape. New York, Springer Publishing Company, 2008, pp 119-149.

18 Rodriguez NE: Exactly How Much Are the Times A-Changing? Newsweek, July 26, 2010, p 56.

19 Hesse BW, Hansen D, Finholt T, Munson S, Kellogg W, Thomas JC: Social participation in Health 2.0. Computer 2010;43:45-52.

-20 Van De Belt TH, Engelen LJ, Berben SA, Schoonhoven L: Definition of Health 2.0 and Medicine 2.0: a systematic review. J Med Internet Res 2010;12:e18.

21 Chou WY, Hunt Y, Folkers A, Augustson E: Cancer survivorship in the age of YouTube and social media: a narrative analysis. J Med Internet Res 2011;13:e7.

22 Bender JL, Jimenez-Marroquin MC, Jadad AR: Seeking support on facebook: a content analysis of breast cancer groups. J Med Internet Res 2011;13:e16.

23 Anderson IK: The uses and gratifications of online care pages: a study of CaringBridge. Health Commun 2011;26:546-559.

24 Baptist AP, Thompson M, Grossman KS, Mohammed L, Sy A, Sanders GM: Social media, text messaging, and email-preferences of asthma patients between 12 and 40 years old. J Asthma 2011;48:824-830.

25 Tung JY, Do CB, Hinds DA, Kiefer AK, Macpherson JM, Chowdry AB, Francke U, Naughton BT, Mountain JL, Wojcicki A, Eriksson N: Efficient replication of over 180 genetic associations with self-reported medical data. PLoS One 2011;6:e23473.

26 Eng TR, Gustafson DH; Science Panel on Interactive Communication and Health: Wired for health and well-being: the emergence of interactive health communication. Washington, DC, US Department of Health and Human Services, US Government and Printing Office, April 1999.

27 Sonnenberg FA: Health information on the Internet. Opportunities and pitfalls. Arch Intern Med 1997;157:151-152.

28 Kemper DW: Trust on the health Internet. Manag Care Q 2001;9:9-18.

29 Jadad AR, Gagliardi A: Rating health information on the Internet: navigating to knowledge or to Babel? JAMA 1998;279:611-614.

30 Shenk D: Data Smog: Surviving the Information Glut, ed 1. San Francisco, Harper Edge, 1997.

31 Werner RM, Asch DA: The unintended consequences of publicly reporting quality information. JAMA 2005;293:1239-1244.
32 Ivanitskaya L, Brookins-Fisher J, O Boyle I, Vibbert D, Erofeev D, Fulton L: Dirt cheap and without prescription: how susceptible are young US consumers to purchasing drugs from rogue internet pharmacies? J Med Internet Res 2010;12:e11

33 Ribisl KM, Williams RS, Gizlice Z, Herring AH: Effectiveness of state and federal government agreements with major credit card and shipping companies to block illegal Internet cigarette sales. PLoS One 2011;6:e16754.

34 Liang BA, Mackey T: Searching for safety: addressing search engine, website, and provider accountability for illicit online drug sales. Am J Law Med 2009;35:125-184.

35 Shani S: E-commerce of pharmaceuticals (in Hebrew). Harefuah 2003;142:372-376, 396397.

36 Chew C, Eysenbach G: Pandemics in the age of Twitter: content analysis of Tweets during the 2009 H1N1 outbreak. PLoS One 2010; 5:e14118.

37 Academy for Educational Development: Genetic Testing Marketing and Communications: A Review of Literature, 1998-2008. Washington, DC, Academy for Educational Development, 2009.

38 Crocco AG, Villasis-Keever M, Jadad AR: Analysis of cases of harm associated with use of health information on the internet. JAMA 2002;287:2869-2871.

39 Surowiecki J: The Wisdom of Crowds: Why the Many are Smarter than the Few and How Collective Wisdom Shapes Business, Economies, Societies, and Nations, ed 1. New York, Doubleday, 2004.

40 Wicks P, Massagli M, Frost J, Brownstein C, Okun S, Vaughan T, Bradley R, Heywood J: Sharing health data for better outcomes on PatientsLikeMe. J Med Internet Res 2010; 12:e19.

41 Meier A, Lyons EJ, Frydman G, Forlenza M, Rimer BK: How cancer survivors provide support on cancer-related Internet mailing lists. J Med Internet Res 2007;9:e12.

42 Hesse BW, O’Connell M, Augustson EM, Chou WY, Shaikh AR, Finney Rutten LJ: Realizing the promise of Web 2.0: engaging community intelligence. J Health Commun 2011;16(suppl 1):10-31.

43 Health Information National Trends Survey Online Database. National Institutes of Health, 2011. http://hints.cancer.gov/.

$\checkmark 4$ Leighton JW, Valverde K, Bernhardt BA: The general public's understanding and perception of direct-to-consumer genetic test results. Public Health Genomics 2012;15:1121.

45 Hesse BW, Nelson DE, Kreps GL, Croyle RT, Arora NK, Rimer BK, Viswanath K: Trust and sources of health information: the impact of the Internet and its implications for health care providers: findings from the first Health Information National Trends Survey. Arch Intern Med 2005;165:2618-2624. 
-46 Gollust SE, Gordon ES, Zayac C, Griffin G, Christman MF, Pyeritz RE, Wawak L, Bernhardt BA: Motivations and perceptions of early adopters of personalized genomics: perspectives from research participants. Public Health Genomics 2012;15:22-30.

47 Eysenbach G: From intermediation to disintermediation and apomediation: new models for consumers to access and assess the credibility of health information in the age of Web2.0. Stud Health Technol Inform 2007; 129(Pt 1):162-166.

48 Eysenbach G: Medicine 2.0: social networking, collaboration, participation, apomediation, and openness. J Med Internet Res 2008; 10:e22.

49 Cameron LD, Leventhal H: The Self-Regulation of Health and Illness Behaviour. London, Routledge, 2003.

50 Glanz K, Rimer BK, Viswanath K: Health Behavior and Health Education: Theory, Research, and Practice, ed 4. San Francisco, Jossey-Bass, 2008.

51 Masley SA, Gillanders DT, Simpson SG, Taylor MA: A systematic review of the evidence base for schema therapy. Cogn Behav Ther 2011, E-pub ahead of print.

- 52 Leventhal H, Weinman J, Leventhal EA, Phillips LA: Health psychology: the search for pathways between behavior and health. Annu Rev Psychol 2008;59:477-505.

53 Leventhal H, Safer MA, Panagis DM: The impact of communications on the self-regulation of health beliefs, decisions, and behavior. Health Educ Q 1983;10:3-29.

54 Leventhal H, Watts JC, Pagano F: Effects of fear and instructions on how to cope with danger. J Pers Soc Psychol 1967;6:313-321.
55 Cameron LD, Marteau TM, Brown PM, Klein WM, Sherman KA: Communication strategies for enhancing understanding of the behavioral implications of genetic and biomarker tests for disease risk: the role of coherence. J Behav Med 2011, E-pub ahead of print.

56 Veenstra DL, Roth JA, Garrison LP Jr, Ramsey SD, Burke W: A formal risk-benefit framework for genomic tests: facilitating the appropriate translation of genomics into clinical practice. Genet Med 2010;12:686693.

57 Burke W, Burton H, Hall AE, Karmali M, Khoury MJ, Knoppers B, Meslin EM, Stanley F, Wright CF, Zimmern RL; Ickworth Group: Extending the reach of public health genomics: what should be the agenda for public health in an era of genome-based and 'personalized' medicine? Genet Med 2010;12: 785-791.

58 Ng PC, Murray SS, Levy S, Venter JC: An agenda for personalized medicine. Nature 2009;461:724-726.

59 Collins FS: NIH Medline Plus: Transforming discovery into health. National Institutes of Health and the Friends of the National Library of Medicine 2010;5:2-3.

60 Collins FS: NIH in the 21st Century: The Director's Perspective. Subcommittee on Health; Committee on Energy and Commerce. Washington, DC, National Institutes of Health, 2010, pp 1-11.

61 Zerhouni E: Extracting knowledge from science: a conversation with Elias Zerhouni. Interview by Barbara J. Culliton. Health Aff (Millwood) 2006;25:w94-w103.

62 Institute of Medicine (US), Committee on Quality of Health Care in America: Crossing the Quality Chasm: A New Health System for the 21st Century. Washington, DC, National Academy Press, 2001.
63 Yong PL: The Healthcare Imperative: Lowering Costs and Improving Outcomes. Workshop Series Summary. Washington, DC, The National Academies, 2010.

64 Wagner EH, Bennett SM, Austin BT, Greene SM, Schaefer JK, Vonkorff M: Finding common ground: patient-centeredness and evidence-based chronic illness care. J Altern Complement Med 2005;11(suppl 1):S7-S15.

65 Olsen LA, Saunders RS, McGinnis JM: Patients Charting the Course: Citizen Engagement in the Learning Health System. Washington, DC, The National Academies, 2011.

66 Venter JC: Multiple personal genomes await. Nature 2010;464:676-677.

67 President's Council of Advisors on Science and Technology: Realizing the Full Potential of Health Information Technology to Improve Healthcare for Americans: The Path Forward. Washington, DC, The White House, 2010.

68 President's Council of Advisors on Science and Technology: Designing a Digital Future: Federally Funded Research and Development in Networking and Information Technology. Washington, DC, The White House, 2010.

69 Cappella JN: Communicating Genetic Risk: Efficacy, Type of Risk, and Narrative Forms. Rockville, MD, Centers of Excellence in Cancer Communication Research. 2010.

70 Olsen LA, Saunders RS, McGinnis JM: Patients Charting the Course: Citizen Engagement in the Learning Health System. Washington, DC, The National Academies, 2011.

71 Goetz T: The Decision Tree: Taking Control of Your Health in the New Era of Personalized Medicine. New York, Rodale, Distributed to the trade by Macmillan, 2010. 